${ }^{\text {I }}$ University of Illinois at Urbana-Champaign,

Estados Unidos

markus.s.schulz@gmail.com

Markus S. Schulz'

\title{
DEBATENDO FUTUROS: TENDÊNCIAS GLOBAIS, VISÕES ALTERNATIVAS E DISCURSO PÚBLICO
}

Tradução de Alexandre Pinheiro Ramos

Existem, provavelmente, tantas definições de pesquisas sobre futuros como de sociologia. Diferentes escolas sociológicas buscaram definir o objeto da sociologia como sendo o comportamento social, ordem social, mudança social ou alguma combinação destes. Virou moda abrir mão de definições ou lançar mão da definição operacional de que sociologia é o que os sociólogos fazem. Afora o que quer que os sociólogos façam, a sociologia pode ser entendida - esse é o aspecto que desejo sustentar aqui - como uma reflexão coletiva sobre as condições de nossa existência social e as possibilidades de mudanças futuras. Um observador pode descrever a sociologia como um espaço no qual ela pensa sobre si mesma, seu passado, presente e futuro.

Provavelmente, é inconteste a afirmação de que o estudo sociológico do passado ou do presente é muito menos controverso que o estudo do futuro. Encontrei vários sociólogos para os quais fazer uma sociologia do futuro seria algo inerentemente enganoso, fútil e, ou ideológico, ou tolo, visto que não podemos conhecer o futuro. Devo, então, apresentar algumas explicações sobre os significados sociológicos de "futuro" e os objetos das pesquisas sociológicas sobre futuros.

Muitas das reflexões nos séculos passados sobre o futuro partiram do princípio de que o mesmo estaria predestinado, predeterminado ou pelo menos progredindo em certa direção que o faria previsível. Antigos documentos históricos apontam para os importantes papéis desempenhados por oráculos e 
profecias em culturas espalhadas pelo globo. A sociologia como disciplina surgiu em uma conjuntura da história ocidental na qual crenças em alguns telos futuros deram espaço à busca positivista de leis sociais, o conhecimento do que se pensava ser o instrumental para gerir, administrar ou libertar a sociedade. A importância do período de formação da sociologia faz com que seja pertinente levar em consideração, pelo menos de forma breve, os trabalhos de alguns de seus fundadores nas influentes tradições britânica, francesa e alemã.

Auguste Comte trouxe à tona o conceito de "sociologia" em um esforço para estabelecê-la como uma "ciência positiva" que iria superar visões de mundo supersticiosas e indicaria à sociedade um caminho baseado na ordem para um futuro melhor (I957 [I848]). Embora Comte seguisse a ideia de seu professor, Henri Saint-Simon, de estudar, da mesma forma positivista, a sociedade como uma natureza, ele rejeitou duramente a utopia socialista de Saint-Simon. Como os contrarrevolucionários franceses católicos Louis de Bonald e Joseph de Maistre, Comte abominava a agitação revolucionária e a anarquia, mas diferentemente deles, pensava que a tecnologia e a ciência modernas não permitiriam nenhum retorno a uma ordem medieval. Comte, assim, imaginou uma reconciliação entre "ordem e progresso", uma ideia que acabou por se destacar como lema na bandeira nacional brasileira. Acreditava que a "estabilidade social" e a "dinâmica social" obedeciam a leis imutáveis de um processo evolucionário que poderia ser descoberto. Ele sustentava que a história era governada pela "Lei dos Três Estados", de acordo com a qual a sociedade encontrar-se-ia em um processo de crescente esclarecimento a partir do estado "teológico" para o "metafísico" e, então, para o "positivo" (I957 [I848]; I855 [1830-42]). Comte encarava este processo como sendo "natural": "Nós estamos sempre nos tornando mais inteligentes, mais ativos e mais amáveis" (I968 [I853]: 60). Ele antevia a sociologia fornecendo o conhecimento sobre as leis sociais que ajudariam as elites esclarecidas a liderar a sociedade na direção de um futuro melhor. Comte elaborou em diversos volumes uma visão altamente detalhada do futuro, repleta de minuciosos pormenores. Tornando-se cada vez mais anti-intelecual, ele chegou ao ponto de propor uma biblioteca definitiva de cem livros que, acreditava, eram os únicos cuja leitura deveria ser encorajada para que não houvesse distrações de meditações mais importantes. Outros planos incluíam uma grande quantidade de feriados públicos em homenagem ao positivismo, o projeto para templos positivistas com determinado número de sacerdotes e párocos que seriam liderados pelo próprio Comte como sumo sacerdote ou pontífice. A despeito de sua retória positivista, Comte não fez praticamente nenhuma pesquisa empírica. Ele pensava em "deduzir" as leis da estabilidade social e da dinâmica social "a partir das leis da natureza humana" (I968 [I852]: 344-345), as quais ele acreditava conhecer por suas próprias experiências. As crescentes especulações sem fundamento de Comte contribuíram para que se desconsiderasse não somente sua produção tardia, como também seus primei- 
ros trabalhos, mesmo que estes tenham sido influentes no sentido de criar formas para estudar a sociedade.

O mais importante fundador da sociologia no Reino Unido foi, provavelmente, Herbert Spencer. Influenciado de modos diferentes por Adam Smith, Charles Darwin e Auguste Comte, Spencer é mais conhecido por sua abordagem evolucionista da sociologia e defensor da competição. Tal qual Smith, Spencer defendia um mercado livre do controle do Estado, exceto quando se tratasse da fiscalização da propriedade e de contratos. Spencer achava-se bastante satisfeito com o status quo social e pensava que o Estado deveria intervir minimamente na vida dos indivíduos, apenas para a proteção destes, permitindo, porém, uma competição irrestrita. Há uma tensão na obra de Spencer entre seu individualismo metodológico, seu uso recorrente de metáforas orgânicas e sua ideia de que as diferentes partes da sociedade possuem funções vis-à-vis uma a outra e ao sistema mais amplo.

Utilizando termos comteanos com intenções normativas, Spencer definiu a "estabilidade social" como o estudo do "equilíbrio de uma sociedade perfeita", enquanto a "dinâmica social" tratava "de forças pelas quais a sociedade avança em direção à perfeição” (I85I: 409). A teoria evolucionista de Spencer difere daquela de Comte em vários pontos. Spencer rejeitava a Lei dos Três Estados, assim como seu foco no desenvolvimento espiritual. Apoiado em abrangentes comparações históricas, Spencer estava cônscio de que a história não seguiria qualquer caminho unilinear. Ele postulava amplas tendências, mas também visualizava a possibilidade constante de reveses ou retrocessos. Diferentemente de Comte, Spencer não afirmava que as "leis" da história poderiam ser reduzidas a algumas poucas e bem delimitadas proposições simétricas. Crucial para ele era a observação de que o aumento da população iria proporcionar uma crescente diferenciação estrutural. O aumento em tamanho e a diferenciação estrutural que verificava caminhavam lado a lado com a transição da sociedade militar para a sociedade industrial. Embora as conquistas militares houvessem contribuído para formar grandes aglomerados sociais, o surgimento da indústria, que necessitava da cooperação e dos laços morais de uma forte sociedade civil, cessaria sua utilidade. Spencer não considerava estas tendências como inevitáveis, mas reconhecia a contínua recorrência de conflitos.

Inspirado pela ideia de "seleção natural" de Charles Darwin (I 859), Spencer cunhou a noção de "sobrevivência do mais forte" (I864), a qual Darwin popularizou mais tarde, quando a acrescentou à sua teoria da evolução das espécies (1869). Spencer considerava os indivíduos como a unidade básica da sociedade, vendo-os passar por um processo de seleção natural que não deveria ser perturbado. Ele acreditava que a natureza por si mesma livrar-se-ia dos "imbecis e preguiçosos", fornecendo, então, com o passar do tempo, populações com um número maior de indivíduos aptos (I864: cap. XIV). Sua forte oposição, de corte normativo, à assistência social, dada fosse pelo Estado ou pela carida- 
de, enraizava-se na crença de que isto acabaria somente por interferir no processo de seleção natural, o qual criaria uma sociedade cada vez mais refinada. "Ajudar os maus a se multiplicar", argumentava, "é, decerto, o mesmo que maliciosamente conceder a nossos descendentes uma multidão de inimigos" (I 864: cap. XIV).

Émile Durkheim, o mais influente herói fundador da sociologia na França, partilhava com Comte hipóteses de evolução social, uma preocupação com a moralidade e a ideia de que o conhecimento sociológico poderia ser utilizado para "gerir" ou administrar a sociedade (I984 [I893]). Diferentemente de Spencer, Durkheim possuía uma visão menos otimista do presente. Acima de tudo, ele preocupava-se com a crise de moralidade que se encontrava na raiz de todos os males modernos. Ainda que clamasse pelo estudo dos "fatos sociais", ele não compartilhava do positivismo ingênuo de Comte (I982 [I895]). E embora altamente comprometido com a investigação empírica, Durkheim não via a ciência como algo absoluto, mas a considerava como uma religião secular, parte de uma visão de mundo contemporânea que também poderia mudar, assim como a cultura mudava.

Ele considerava "o pensamento científico somente [como] uma forma mais aperfeiçoada de pensamento religioso" (I965 [I9I 2]: 43I). O objetivo de Durkheim era reconciliar o positivismo com a moralidade em seu projeto de "ciência da moralidade" (I965 [I9I2]). Embora costumasse escrever como se possuísse uma visão unilinear da história, não acreditava em determinismo histórico. Para ele, nem as mudanças na moral, nem as mudanças na sociedade possuíam necessariamente uma direção. Considerava a moral como sendo formada, transformada e mantida por razões de "ordem experimental" (I984 [I893]: xxvi). Como Tocqueville (I990 [I835-40]), passou a considerar o individualismo como o culto central da sociedade moderna, como uma religião moderna.

Durkheim observou em seu primeiro estudo sobre A divisão do trabalho social (I984 [1893]) que os costumes tradicionais e os laços sociais estavam se afrouxando, porém verificou, em seu subsequente estudo diacrônico e sincrônico das taxas de suicídio em diferentes países desenvolvidos do Ocidente, que uma nova moral adequada a uma sociedade crescentemente diferenciada ainda não havia surgido (I966 [1897]). Durkheim diagnosticou a diferenciação social como sendo a tendência dominante de seu tempo.

Causou-lhe uma grande preocupação ver a solidariedade social mudando de "mecânica" para "orgânica" sem a emergência de uma adequada moral unificante que pudesse ligar indivíduos diferentes do modo como postulara. Neste sentido, seus estudos sobre moral e instituições estavam direcionados para a identificação dos mecanismos pelos quais os costumes individuais eram moldados de modo que tanto a moral como as instituições poderiam ser reconfiguradas (I965 [I9I2]; I990). Embora estando altamente comprometido com a investigação da integração normativa, sua abordagem sofre com a relativa ne- 
gligência de fenômenos tais como interesses, poder, dominação ou o impacto do processo de acumulação de capital sobre a sociedade.

Ainda que Durkheim não tenha conseguido investigar de forma mais sistemática a injustiça econômica e o autoritarismo, ele defendia uma sociedade integrada com uma moral universal (I965 [I9I2]: 493). Seu estudo sobre As formas elementares da vida religiosa levaram-no a ver na "vida coletiva", especialmente em momentos de "efervescência coletiva", o nascimento de ideais que poderiam criar ou recriar a sociedade (I965 [I9I2]).

Diferente de Durkheim, Karl Marx via no capitalismo o problema da época, a causa da alienação e do sofrimento das classes excluídas e exploradas (I978 [I844]; I978 [I848]; I978 [I857-I858]). Contudo, Marx via com otimismo o futuro. Os antagonismos inerentes ao capitalismo, dizia ele, seriam resolvidos por uma revolução proletária que criaria uma ordem social universalmente livre erigida sobre os desenvolvidos meios de produção. Sendo tanto um cientista como uma ativista sem fazer uma estrita separação entre estes papéis, todo o seu trabalho era guiado por um compromisso ético por justiça social e liberdade. Ainda assim, suas obras também refletem tensões em como conceitualizar o futuro. Enquanto Hegel, junto com outros filósofos idealistas e o Comte tardio, concebera a história como um processo de aprendizagem em direção a um esclarecimento cada vez maior, Marx pensou em colocá-lo de cabeça para baixo com uma virada materialista, porém manteve o método dialético de Hegel e os princípios básicos de sua filosofia da história (I978 [1843], I978 [1845-1846]). Marx estudou com atenção os escritos do moralista e economista político escocês Adam Smith (2003 [I776]), no entanto rejeitou sua assunção fundamental de que a "mão invisível" do mercado seria uma força positiva (I867).

Marx, junto com seu colaborador, Engels, sugeriu no Manifesto comunista (I978 [1848]) que as leis da história apontariam para um triunfo necessário do proletariado oprimido sobre a burguesia. Rejeitando o socialismo utópico de Henri de Saint-Simon, Charles Fourier e outros, Marx pouco elaborou como seria uma futura sociedade comunista além da ideia de que poria fim à alienação juntamente com a exploração e o Estado, promovendo liberdade para todos. De acordo com seu modelo de que as ideias eram reflexo das infraestruturas, Marx acreditava que o momento para visões mais concretas ainda não chegara, o que só aconteceria em uma etapa histórica mais adiantada. Marx pensava, como Hegel, que o presente continha a semente para o futuro a partir da qual ele iria dialeticamente desdobrar-se. Se tal semente poderia desenvolver-se em uma direção predeterminada ou com um amplo leque de possibilidade, fica em aberto para diferentes interpretações. A afirmação sobre o caráter inevitável do socialismo nos escritos ativistas de Marx poderia ser vista como mera retórica para encorajar a luta contra a opressão. Em seus escritos históricos mais empíricos, ele indicava claramente que inexistiam automatismos históricos, havendo bastante espaço para ações contingentes (I978 [I852]; I978 [I87I]). 
Marx argumentava, em sua décima-primeira tese sobre Feuerbach, que "os filósofos, até o momento, limitaram-se a interpretar o mundo de diversas maneiras; o objetivo agora é transformá-lo" (I978 [1845]). Criticava a filosofia idealista por unicamente pensar o mundo de forma contemplativa, sem reconhecer seu papel no mundo ou buscar orientá-la para a mudança. Marx, como um ativista, acreditava no poder da ação criativa, mas ele também reconhecia que estruturas mais amplas e o peso do passado cerceavam sua influência. Em um comentário famoso, notou que "os homens fazem a história, mas não fazem como a desejam" (I978 [1852]).

Sobretudo em seus escritos político-ativistas, Marx abraçou um determinismo histórico um tanto esquemático (I 978 [I848]; ver I 978 [I859]; 1978 [1867]). A mudança social surgia como o resultado necessário da lógica interna do processo de acumulação de capital. Contradições sociais polarizar-se-iam ao ponto de que seria inevitável uma sublevação da classe até então excluída e a superação da antiga ordem. Há uma tensão entre o modelo de determinismo histórico e os escritos históricos de base empírica de Marx (I978 [1852]; I 978 [I87I]), ainda que estes possam ser lidos de ambas as formas: como carentes de determinismo e como um esforço para provar como as ações resultam de interesses determinadas por posições de classe.

Ao elaborar estudos históricos de grande amplitude sustentados por sistemáticas comparações diacrônicas e sincrônicas, Max Weber desenvolveu um complexo modelo de mudança social. Ele levava em conta uma pluralidade de percursos históricos, cada um resultado de uma multiplicidade de fatores atuantes (I923; I978; I99I [I905]). Uma das forças de transformação que enfatizou em sua Ética Protestante (I99I [1905]) são as ideias religiosas - uma afirmação que teóricos materialistas atacaram com bastante fervor. Weber, no entanto, não pretendia substituir o materialismo com um idealismo que ele considerava igualmente unilateral. Antes, buscava apresentar processos históricos como uma inter-relação de forças, ideais e materiais, de ações e instituições. Contudo, afora sua teoria sobre o carisma, um fenômeno um tanto incomum, Weber não conseguiu fornecer um tratamento mais sistemático das ações que produzem mudanças sociais (1958; I978; Joas, I992).

Tal qual Marx, Weber reconhecia na inversão da relação entre meios e fins uma causa para a profunda alienação. No entanto, para ele, diferentemente de Marx, o capitalismo era quase universal, reservando a noção de "capitalismo racional" para sua forma mais moderna (1923). Liberto do determinismo histórico como um fiador metafísico, mas ainda assim desprovido de um modelo para a ação racional capaz de produzir normas, Weber tornou-se um tanto pessimista sobre o futuro. Ele via a racionalização como a ameaça que, em última análise, asfixiaria a ação criativa livre e responsável. Em sua visão, a cultura ocidental produziria "especialistas sem espírito, sensualistas sem coração" (I99I [I905]: I82); a racionalidade ocidental tornar-se-ia a "jaula de fer- 
ro" - na famosa tradução de Talcott Parsons (I99I [I905]) da expressão "stahlhartes Gehäuse", "rija crosta de aço" - que confinaria a conduta individual.

Ainda que Weber defendesse uma separação estrita entre os compromissos científico e político, isto não o impediu de reconhecer que valores informavam a escolha das questões perseguidas pela pesquisa acadêmica, ou de abraçar os valores do nacionalismo liberal em seu papel como político e intelectual público (I99I [I904]; I99I [I9I7]). Temendo uma burocratização ainda mais asfixiante, Weber defendia em seu tempo uma democracia plebiscitária com liderança, a qual, esperava, permitiria que líderes capazes de equilibrar princípios e a realidade moldassem os futuros de maneira criativa (I958: I 29; Mommsen, I963).

A despeito das diferenças fundamentais em seus aparatos teóricos e hipóteses, assim como nos diagnósticos específicos de seu tempo e expectativas futuras, os mais proeminentes pais fundadores da sociologia partilhavam uma forte orientação para o futuro e uma disposição audaciosa para o engajamento em questões normativas sobre futuros preferíveis. Enquanto a sociologia desenvolvia-se em uma disciplina acadêmica com seus próprios departamentos em universidades pelo mundo, ela não apenas expurgou os excessos especulativos de seu período de formação, como também deixou de lado evidentes engajamentos normativos, e com isto, a explícita orientação para o futuro. Ainda assim, o colapso das suposições deterministas abre novas possibilidades para o ressurgimento de uma sociologia de corte crítico voltada para o futuro.

A crença em um futuro em aberto é a marca distintiva de nossa consciência sobre o tempo. Como argumentou o historiador Reinhart Koselleck (I989), na modernidade o "espaço de experiência" e o "horizonte de expectativa" dissociam-se cada vez mais. Esta contingência fundamental abre o horizonte do possível para a criação social e política - o que é, poderia ter sido diferente. A realidade existente poderia ter sido moldada de outra forma por meio de ações humanas não-determinadas, de maneiras mais ou menos reflexivas, assim como de modos mais ou menos cooperativos ou conflitantes. Esta consciência acerca da contingência reflete-se na sociologia pela ênfase crescente na "agência humana" (Emirbayer \& Mische, I998) e na "criatividade da ação" (Joas, I992).

Como o futuro pode ser sociologicamente estudado quando ele é visto agora como inerentemente contingente e imprevisível? Segue, aqui, uma definição geral que pode servir como um ponto de partida: a pesquisa sobre futuros pode ser compreendida como uma parte da sociologia cujo foco recai sobre a dinâmica da imaginação e criação do futuro, tendências atuais, cenários possíveis e prováveis e suas implicações sociais. Pode-se distinguir quatro grandes abordagens nos estudos sobre futuros: (I) previsões específicas, tais como projeções de tendências demográficas atuais ou as chamadas Entrevistas Delphi com especialistas sobre suas expectativas acerca de desenvolvimento e pesquisa (seus pioneiros foram Gordon \& Helmer, I964; para uma aplicação 
mais recente ver, por exemplo, Beck, Glotz \& Vogelsang, 2000); (2) construção de cenários ou simulações de futuros alternativos que parecem possíveis ou prováveis (para um trabalho pioneiro, consultar Meadows et al., I972; para exemplos mais recentes, Schulz, I999; 200Ib); (3) estudos de imaginação social e criação de futuro, isto é, pesquisas empíricas sobre as imagens do futuro formuladas no passado ou no presente (ver Masini, I983; Bell, I997a; Slaughter, 2002; Wright, 2010), bem como acerca dos processos pelos quais tais visões são construídas e podem ou não ter eficácia (ver Mannheim, I936; Beilharz, 2009; Castoriadis, I99I; Melucci, I996; Wright, 2010); e (4) pesquisa normativa ou normativo-analítica sobre futuros desejáveis (Bell, I997b), incluindo pesquisas sobre a relação entre valores e futuros (ver Bachika \& Schulz, 20I I). A distinção ideal-típica entre estas abordagens pode servir como ilustração do alcance das pesquisas sociológicas sobre o futuro. É claro que estas abordagens não precisam ficar isoladas uma das outras, podendo dialogar entre si, e em trabalhos empíricos, muitos projetos utilizam-se de mais de uma abordagem.

\section{PESQUISA SOBRE FUTUROS E DEBATE PÚBLICO: PARA ALÉM DO POSITIVISMO EXPERTOCRÁTICO}

Como a pesquisa sociológica sobre o futuro relaciona-se ou pode se relacionar com o debate público? A partir da bastante debatida terminologia de Michael Burawoy (2005), argumento que estudos utilizando uma daquelas quatro abordagens podem ser direcionados a públicos "acadêmicos" ou "extra-acadêmicos" e conduzidos de forma "instrumental" ou "reflexiva", isto é, eles podem ser realizados tanto como sociologias "profissional" ou "política", como sociologias "crítica" ou "pública" - nos termos de Burawoy. Decerto tem ocorrido uma grande afinidade entre previsões e política, assim como entre estudos do imaginário e análises críticas. No entanto, a despeito destas afinidades, o debate público pode se valer destas quatro abordagens. Previsões específicas podem servir ao público como advertências sobre o que pode acontecer caso nenhuma contramedida seja adotada. A construção de cenários é acrescentada a visões específicas e extrapolações de caminhos alternativos. Estudos do imaginário trazem noções de poder e podem se relacionar a atores sociais subalternos com projetos contra-hegemônicos. E pesquisas sobre valores podem contribuir para esclarecer as escolhas valorativas que geralmente estão apenas implícitas em futuros alternativos.

Historicamente, a relação entre pesquisa sobre futuros e o público parece ter se desenvolvido de modos e em fases distintas. Os estudos convencionais de futuros frequentemente orientavam-se para uma elite política e seus think-tanks - de modo mais visível na década de I950, e menos hoje em dia. Agências governamentais, instituições e fundações aliadas a partidos políticos e empresas de negócios foram aquelas que mais comumente solicitavam e pagavam por estudos específicos de futuros. Não é, então, de surpreender que uma grande parte dos estu- 
dos de futuros estava direcionada às elites políticas e empresariais. Em casos nos quais eles eram encomendados por empresas de negócios, os resultados permaneciam geralmente em sigilo ou o acesso a eles era restrito pela cobrança de altas taxas. Bastante comum era a tônica de alguns estudos feitos por contrato e de estudos preparados em ambientes acadêmicos os quais deveriam fornecer opiniões de "experts" e "fatos" sobre o futuro de modo que os responsáveis pelas decisões, ou as assim chamadas "autoridades competentes", pudessem fazer e guiar suas decisões. De fato, estes membros da elite são atores poderosos e relevantes, de modo que a capacidade de se dirigir a eles proporciona considerável influência. Ainda assim, esta visão elitista repousa sobre uma noção restrita de democracia, semelhante àquela defendida por Schumpeter (I975 [I950]) e outros, na qual os sujeitos elegem seus governantes de tempos em tempos sem ter mais nada o que fazer. Esta visão elitista acha-se equivocada em, pelo menos, dois aspectos: empírico e normativo. Ela negligencia as iniciativas dos cidadãos comuns, movimentos sociais e redes subalternas - atores comuns detentores de menor prestígio formal e poder institucional, mas ainda assim com posições morais, voz criativa e potencial de impacto.

A relação entre a pesquisa sobre futuros e o público modificou-se durante seus anos de expansão no fim da década de I960. Surgiu uma torrente de livros populares sobre o futuro do então longínquo ano 2000, incluindo aqueles de Daniel Bell (I968), Robert Jungk \& Johan Galtung (I969), Herman Kahn \& Anthony Wiener (I967). Muitas das publicações mais populares baseavam seu otimismo no progresso tecnológico e geralmente tinham como foco os benefícios advindos das tecnologias da era espacial e os bens de consumo em massa (visão geral em Bell, I997a). Este otimismo reforçava-se pelas experiências da vida cotidiana. Avanços tecnológicos tais como o pouso da nave Apollo e os primeiros passos do homem na Lua foram transmitidos pela televisão para uma audiência mundial. Tecnologia produzida em massa, incluindo automóveis e uma pletora de equipamentos domésticos, tornou-se acessível a um maior número de pessoas nos países mais ricos. Esperava-se que a Revolução Verde alimentaria o Terceiro Mundo e acreditava-se que a tecnologia seria distribuída a toda a população mundial.

Contudo, este otimismo tecnológico logo cederia espaço a uma visão mais pessimista. Uma série de fatores heterogêneos levou a tal mudança. A crise do petróleo, em princípios da década de i970, levou a uma recessão mundial. As consequências desta interrupção abrupta do crescimento foram sentidas não somente por motoristas, mas também por consumidores ao redor do mundo. Os Estados de bem-estar social do Primeiro Mundo conheceram uma crise de legitimidade. O compromisso histórico entre capital e trabalho foi posto à prova quando o crescimento do bolo da redistribuição de riquezas diminuiu ou mesmo recuou (Offe, I987). O Relatório do Clube de Roma feito por Dennis Meadows e seus colaboradores (Meadows et al., I972) trazia uma incisiva ad- 
vertência sobre os Limites do crescimento e tornou-se famoso ao tocar os primeiros acordes de preocupação. Movimentos ambientalistas começaram a surgir em um número cada vez maior de países industrializados, criticando o abuso dos recursos naturais do Planeta. Outros críticos chamaram a atenção para o espectro da Terceira Guerra Mundial. Os crescentes arsenais de armas nucleares multiplicaram sua capacidade destrutiva. A tecnologia passou a ser vista como uma ameaça iminente pelo movimento pela paz na Guerra Fria. O Terceiro Mundo desenvolveu a Teoria da Dependência (Amin, I977; Cardoso \& Faletto, I979; Frank, I967), a qual argumentava que as teorias da modernização e as suposições redistributivas do desenvolvimento eram ingênuas e que o Terceiro Mundo se encontrava em um sistema desigual que não permitia quaisquer melhorias por razões sistêmicas. Esta situação levou ao que foi chamado por Jürgen Habermas (I985) de "esgotamento das energias utópicas" e ao enfraquecimento do boom dos estudos orientados para o futuro.

Durante as décadas de I980 e I990, a pesquisa acadêmica sobre futuros travou intensas batalhas para adquirir respeitabilidade profissional e deu grandes passos no refinamento de seu instrumental metodológico e na expansão de seu alcance substancial. Grande parte dos créditos vão para o trabalho de Wendell Bell (I997a e b), Elise \& Kenneth Boulding (I995) e Jan Nederveen Pieterse (2000). Ainda assim, enquanto a sociologia respondia às pressões institucionais com um recrudescimento positivista, esforços em geral para um engajamento no futuro continuavam diminuindo. Doutrinas econômicas neoliberais passaram a dominar o debate público e político sobre o futuro desde a era Reagan-Thatcher e, sobretudo, depois do fim da Guerra Fria. As investidas atuais por uma sociologia pública nas associações Americana e Internacional de Sociologia podem fornecer uma abertura para a sociologia se impor e para alimentar e inspirar o discurso sobre o futuro.

Este amplo esboço histórico pode, agora, servir como um pano de fundo para uma reflexão mais detalhada sobre a relação entre a atual pesquisa de futuros e debates públicos, explorando exemplos específicos com abordagens diferentes.

\section{PREVISÕES E CONSTRUÇÃO DE CENÁRIOS: O IMPACTO DA MUDANÇA CLIMÁTICA}

O primeiro exemplo é um projeto de pesquisa interdisciplinar sobre a mudança climática, chamado de KLIMU. Este projeto de larga escala foi bancado por diferentes agências dos governos federal e estadual alemães com foco no impacto a longo prazo sobre o Estuário Weser, na região costeira do noroeste alemão (ver Schuchardt \& Schirmer, 2005). Dezenas de pesquisadores de disciplinas como climatologia, oceanografia, ciências do solo, agricultura, negócios, economia e sociologia trabalharam juntos e desenvolveram um modelo econométrico re- 
gional para gerar previsões específicas até os anos de 2020 e 2050. Três cenários específicos incluíam (I) uma simples extrapolação de tendências atuais; (2) um abandono das tendências atuais e das contramedidas, iniciando em 2020; e (3) um direcionamento mais ativo com contramedidas tomadas imediatamente. Como o único sociólogo do projeto, desenvolvi um conjunto de indicadores de mudança social que nós, então, operacionalizamos e integramos ao modelo econométrico (Schulz, I999; 200Ib). O modelo permitiu comparações entre os custos para abandonar áreas propensas a inundação e para a construção de grandes diques, assim como o que os contribuintes poderiam poupar caso o efeito estufa, com suas mudanças climáticas resultantes, fosse evitado. Uma exibição pública do problema dos custos foi, em princípio, pensada, mas ela não recebeu os fundos necessários. Este projeto piloto focalizava a região costeira alemã, mas permitia comparações com outras regiões, incluindo aquelas com maior propensão a serem afetadas mais fortemente por mudanças climáticas.

O combate às causas da mudança climática necessita da cooperação global dos governos nacionais. Ainda assim, os governos dos países mais industrializados ou em processo de rápida industrialização mostram-se um tanto relutantes sobre isto, visto que as consequências não são imediatamente identificáveis no período de uma legislatura. Para que os governos se mostrem mais dispostos a negociar tratados que busquem mitigar as mudanças climáticas, é preciso que haja uma pressão popular que só poderá surgir a partir de debates voltados para futuros a longo prazo.

O público geral na Alemanha e em grande parte da Europa Ocidental acha-se bastante convencido de que o efeito estufa leva ao aquecimento global, ao aumento do nível do mar e a mudanças de padrões climáticos. O movimento ambientalista é particularmente forte na Alemanha. Desde meados da década de i980, o Partido Verde passou a formar coalizões com o governo estadual e federal. Companhias que desenvolvem e produzem tecnologias para o uso de energia renovável foram subsidiadas e tornaram-se, com o tempo, uma força econômica.

Esta é uma situação bem diferente dos EUA, de longe o maior poluidor per capita, onde a administração Bush negou e impediu que cientistas de suas próprias agências falassem sobre o problema (Revkin, 2004; Shulman, 2006). Poderosos lobbies do petróleo e carvão impediram a maioria das medidas que eram defendidas por um movimento ambientalista relativamente fraco. A opinião pública tem mudando apenas recentemente, sobretudo graças à amplamente divulgada campanha multimídia de $\mathrm{Al}$ Gore. Utilizando sua visibilidade nacional de ex-vice-presidente e candidato à presidência, Gore saiu em uma extensa turnê de palestras, escreveu um livro popular (Gore, 2006) e fez um filme ainda mais popular (Uma verdade inconveniente, dirigido por Davis Guggenheim, 2006).

O Prêmio Nobel de 2007, dividido com o Painel Intergovernamental sobre Mudanças Climáticas (IPCC, em inglês), foi, assim, um reconhecimento a Gore, 
o que veio, além disto, a reforçar a sua causa. Tem-se, aqui, uma situação na qual há um consenso esmagador entre os cientistas sobre um perigoso cenário futuro, mas em que o conhecimento sobre o mesmo somente adentrou o debate público por meio do esforço conjunto de uma bem orquestrada campanha midiática com jeito de celebridade.

Comparando as situações na Alemanha e nos EUA, pode-se argumentar que forças políticas e econômicas podem facilitar ou impedir o fluxo de informação da academia, e se elas impedirem o debate público, é preciso, então, jogar conforme as regras da mídia como sua guardiã. O conhecimento disponível só adquire eficiência quando ele adentra discursos mais amplos.

\section{FUTUROS ALTERNATIVOS: IMAGINAÇÃO, MOVIMENTOS E VOZES SUBALTERNAS}

Enquanto o primeiro conjunto de exemplos enfatizou o papel dos pesquisadores como provedores de conhecimento e definidores de agendas, o próximo deverá sublinhar o contrário: pesquisadores no papel de ouvintes. A epistemologia materialista há muito argumenta que o conhecimento encontra-se enraizado nas condições materiais concretas de vida. A teoria marxista de classes diz que a experiência vinculada a posições sociais específicas permite percepções que podem estar vedadas a outras. Sociólogos que se voltam para o futuro reconhecem a habilidade dos movimentos em criar conhecimento crítico, visões e projetos. Orlando Fals Borda (I987) desenvolveu a "pesquisa participante ativa" como um método para "romper com o monopólio" do conhecimento dominante. Alain Touraine (I98I) caracterizou os movimentos sociais como os "olhos" e "vozes" da sociedade. Alberto Melucci (I996) chamou-os de "profetas" no sentido de que eles anunciam o que ainda está por vir, apontam os problemas e formulam visões sobre o futuro. Grupos de pesquisadores colaboram nestas abordagens com ativistas e públicos dissonantes no diagnóstico das condições do presente e na discussão de objetivos, estratégias e táticas para engendrar mudanças. Um exemplo clássico de tal "intervenção sociológica" foi o engajamento do grupo de Touraine com o movimento polonês Solidariedade na década de 1980 (ver Touraine et al., I983).

Outros exemplos recentes podem ser encontrados no famoso caso do movimento zapatista. Os zapatistas levantaram armas na região sudeste do estado mexicano de Chiapas em I994 no dia em que o Tratado Norte-Americano de Livre Comércio (NAFTA) entrou em vigor. Os camponeses indígenas insurgentes protestaram contra o NAFTA e exigiram reforma agrária, direitos para os indígenas e participação democrática. Cientistas sociais estiveram envolvidos de várias formas e assumindo papéis variados. Em nível nacional, um grande número de sociólogos, antropólogos, cientistas políticos, historiadores e economistas mexicanos aproximou-se dos zapatistas por meio de conversas 
sobre reformas nacionais, atuou ativamente como conselheiros dos rebeldes durante os complicados processos de negociação com o governo federal mexicano, e serviram de comentaristas nos principais jornais do país. Da mesma forma, sociólogos, antropólogos e cientistas políticos de outros países foram para o México para estudar as dimensões local e nacional do conflito, assim como a expansão transnacional do movimento; acadêmicos ativistas como Yvon LeBot, na França, Ulrich Brand, na Alemanha, e David Holloway, na Inglaterra, levaram a sério o projeto zapatista e tomaram-no como fonte de inspiração para suas análises sobre a globalização. O porta-voz zapatista, subcomandante Marcos, estudara sociologia e estudos de mídia. Sua dissertação de mestrado e artigos posteriores mostram a influência de pensadores críticos como Paulo Freire, Antonio Gramsci, Louis Althusser e Michel Foucault. De certo modo, a sociologia pública tornou-se prática.

A inicialmente pequena insurgência no Sul Global inspirou uma rede transnacional. Os zapatistas reuniram-se em Encontros Intercontinentais de ativistas de base e intelectuais e convocaram uma rede "Contra o Neoliberalismo e a Favor da Humanidade". Os camponeses maias que se revoltaram não eram pessoas "atrasadas", mas o catalisador de um desafio à forma dominante de globalização. Apanhando a deixa dos zapatistas, uma nova geração de ativistas começou a protestar contra o modelo neoliberal de globalização e suas instituições mais visíveis, como o Banco Mundial, o Fundo Monetário Internacional, a Organização Mundial do Comércio e o G8 durante seus encontros em Praga, Seattle, Washington e Genebra. A pesquisa sobre os zapatistas mostra como um ator subalterno supostamente "fraco" pode desafiar um regime nacional consolidado e um modo e globalização hegemônico. A luta dos zapatistas por dignidade contribuiu para a abertura de espaços para dissensos e para a imaginação de futuros alternativos (Schulz, I998; 2007a). Por outro lado, suas limitações são evidentes, sobretudo quando se considera quão facilmente a "Guerra ao Terror" pós-I I de setembro colocou de lado a atenção internacional a este movimento.

\section{VALORES E FUTUROS DESEJÁVEIS}

Pesquisas normativas e normativo-analíticas sobre futuros ocupam-se com as implicações sociais de futuros prospectivos. Em qual direção queremos desenvolver nosso mundo? Quais cenários são desejáveis? Como as preferências podem ser justificadas? Ao tratar destas perguntas, a recente pesquisa sobre futuros direcionou boa parte de sua atenção para a questão dos valores (Bell, I997b; Bachika \& Schulz, 20I I). Enquanto sociólogos demonstraram que as queixas recorrentes sobre um declínio dos valores morais não passaria de um mito (ver, por exemplo, Boudon, 2002), ainda existe uma grande discordância sobre como conceitualizar a relação entre valores diferentes e visões de futuros. Di- 
zendo de forma mais enfática: estará a humanidade condenada a uma disputa de valores, ou valores comuns poderiam servir como guia para um futuro mais pacífico e harmonioso?

Samuel Huntington (I996) ganhou bastante notoriedade com sua visão do futuro marcado por valores irreconciliáveis e por um inevitável "choque de civilizações". Huntington foi corretamente criticado por seu evidente viés etnocêntrico e por negligenciar as mudanças e relações históricas (ver, por exemplo, Casanova, 20I I: 258-263). Ainda assim, a maneira recorrente de descrever, na esfera pública, estes choques culturais como "inevitáveis" pode fazer disto uma profecia que se autorrealiza. Guerreiros culturais promovem incisivas distinções entre "amigos" e "inimigos" e utilizam o medo do outro para cavar trincheiras cada vez mais profundas.

Uma posição contrária a valores universais como base para o futuro foi fortemente defendida por Wendell Bell (I997b). Bell chamou a atenção para vários estudos sociológicos e antropológicos que elaboraram conjuntos de valores comuns e, num segundo momento, construídos a partir do método filosófico da "implicação epistêmica" de Keekok Lee (I985) como formas de avaliar objetivamente declarações sobre valores. Este não é momento para entrar em detalhes sobre estas questões, mas pelo menos dois problemas devem ser levantados. Em primeiro lugar, os esforços para definir conjuntos de valores universais básicos são afetados por contra-argumentos empíricos ou por acusações de que eles impedem o escrutínio empírico por meio de excessivas abstrações e a inclusão de conceitos que possuem significados, se não concorrentes, conflitantes para diferentes atores. Por exemplo, a proibição de matar aproxima-se de ser algo universal, mas inúmeras exceções controversas tais como relacionadas a guerra, autodefesa, pena capital, honra, nascituros, animais e suicídio mostram que seu exato significado desdobra-se em contextos específicos. Valores relacionados à lealdade como patriotismo podem ser encontrados em toda parte, sendo importantes para a coesão do grupo; mas eles excluem outros e possuem, assim, significados opostos. Em segundo lugar, não está claro se o método de Lee pode ser utilizado por qualquer um que não partilhe da mesma episteme. As suposições racionalistas desta abordagem levaram pesquisadores como Reimon Bachika (20I I) a procurar por valores comuns sob camadas de simbolismo. De modo semelhante, o teólogo Hans Küng (I999) propôs o projeto de uma ética global mediante o diálogo ecumênico. Contudo, as mesmas questões que foram direcionadas contra Bell aparecem novamente, isto é, se valores comuns podem ser definitivamente identificados e se pessoas não identificadas com preceitos ecumênicos estariam propensas a tomar parte neste projeto. De forma mais contundente, José Casanova (20 I I: 253-58) argumentou que o projeto cosmopolita de um futuro comum baseado nos modernos valores ocidentais acha-se teórica e empiricamente equivocado em suas suposições sobre padrões universais de desenvolvimento e secularização, e engana-se por 
seu subjacente expansionismo ocidental. Casanova adverte que exigências hegemônicas para que se copie os padrões ocidentais, tais como pressionar o Islã a se tornar uma religião "privada", podem resultar apenas em mais respostas violentas. Se a noção cada vez mais popular de "modernidades múltiplas" de Shmuel Eisenstadt (2002) é capaz de fornecer um meio para superar este dilema ou se é preciso ir além de todo o discurso de modernidade, isto é algo a ser debatido. Uma visão ampla da democracia global precisa reconhecer a diversidade cultural e manter flexíveis os procedimentos para o diálogo.

O trabalho filosófico de Wolfgang Welsch (I996) sobre a "razão transversal" pode fornecer, aqui, uma ferramenta conceitual útil notadamente porque ele centra a razão na relação e na comunicação, ficando livre de essencialismos. Uma noção transversal da razão precisa de diálogo contínuo; valores não são reificados, mas discutidos em situações e relações específicas. A noção de diálogo pode contribuir para evitar o dogmatismo de valores. Preferências por valores e visões do futuro não podem ser presumidos, mas sim acordados em diálogos públicos.

\section{CRIANDO PÚBLICOS}

Permanece a questão sobre quais são os espaços para os públicos entabularem diálogos de base não apenas em níveis local e nacional, mas também transnacional e global (ver Dewey, I927; Habermas, I992 [1962]; Calhoun, I992; Cohen \& Arato, I992; Emirbayer \& Sheller, I999 sobre a ideia de esfera pública). Se a esperança por harmonia e paz mundial já foi projetada sobre os trilhos de trem, rádio e televisão quando estas ainda eram invenções recentes, as tecnologias de mídia relacionadas à Internet deram margem ao ressurgimento destas esperanças. As novas tecnologias de mídia não só aceleram a globalização dos mercados e produção, mas também fornecem novos ambientes para debates globais.

A ideia de "aldeia global" de Marshall McLuhan (I964), originalmente cunhada no contexto das primeiras mídias eletrônicas de massas, conhece um renascimento. Artigos e livros acadêmicos anunciam a emergência da "sociedade civil global" e celebram a Internet como um meio para reconciliação global. Contudo, estas grandes esperanças por diálogos equitativos globais já estão perdendo espaço para ceticismos crescentes e medos distópicos vis-à-vis uma comercialização intensa, acesso desigual, esvaziamento dos patrimônios culturais e novos mecanismos de segurança.

Embora uma parte substancial das atuais pesquisas sobre futuros seja direcionada para as novas mídias, seu desenvolvimento tecnológico é, geralmente, visto como um progresso levado adiante por especialistas sem muito espaço para escolhas valorativas ou debate político. A intenção normativa de uma abordagem diferente é indicar os interesses nos desenvolvimentos atuais e desmascarar as escolhas valorativas que se fazem presentes na moldagem 
social das novas tecnologias de mídia antes que elas se cristalizem (Schulz, 200Ia; 2002; 2007b; 2009). A criação daquilo que Robert Latham \& Saskia Sassen (2005) chamam de novas "formações digitais" não apenas envolvem problemas tecnológicos stricto sensu, mas, em alguma medida, uma mistura de questões técnicas e legais. E estas são inerentemente políticas. Elas incluem perguntas sobre como distribuir acesso e conhecimento especializado, como proteger a privacidade e como prevenir governos ou corporações "big brother" de se apropriarem de bens comunicativos.

A formação de públicos é o resultado de embates mais ou menos contenciosos e, como tal, em constante mudança. De um lado, interesses corporativos encontram-se, normalmente, mais equipados com recursos e com maior acesso aos responsáveis pelas leis e aos negociadores de tratados internacionais. Por outro lado, os usuários das novas mídias e as iniciativas da sociedade civil podem ampliar sua influência por meio da imaginação criativa e dos esforços para fazer com que decisões imbuídas de valores até então implícitos sejam levadas ao debate político.

Pesquisas sobre futuros que tratam de trajetórias alternativas no desenvolvimento de novas paisagens midiáticas globais podem indicar os interesses e as escolhas valorativas disponíveis. Esta é uma tarefa de pesquisa bastante importante justamente porque trata das precondições para um futuro diálogo global. Uma sociedade mundial democrática não pode ser construída sem as condições democráticas para uma comunicação global.

\section{CONCLUSÃo}

A relação entre as pesquisas sociológicas sobre futuros e debate público é complexa, modificando-se ao longo do tempo e com divergências entre contextos nacionais e substantivos. Sem almejar à elaboração de um sumário destas relações, é possível chegar a algumas conclusões parciais a partir do que foi exposto anteriormente que servirão como pontos de partida para outras discussões. A pesquisa sobre futuros não apenas leva ao debate público um conhecimento que é direcionado para o futuro; ela também intervém de modo a modificar agendas políticas ao apontar para futuros alternativos e os interesses de cenários competitivos. Além disto, a intervenção sobre um público já existente não é o bastante, havendo, também, a necessidade de se trabalhar para que se constituam novos públicos. A ideia de uma esfera pública universal aberta possui sua força normativa, mas considerada empiricamente, os públicos têm limites, algumas vezes visíveis, outras vezes invisíveis. Dentre as principais suposições de uma pesquisa sobre futuros criticamente engajada, acha-se o enraizamento do conhecimento, dos valores e da imaginação na experiência social vivida. Este é o motivo por que se deve ouvir não apenas os atores que compõe as elites, mas também os de base, os marginalizados e oprimidos. Con- 
tinua sendo uma tarefa crucial criar públicos nos quais as aspirações, sonhos e esperanças dos excluídos não sejam mais descartadas.

A relação da sociologia com o debate público pode se beneficiar de uma perspectiva voltada para o futuro que não se abstém de atacar os grandes desafios do presente. O futuro não está apenas acontecendo, ele é feito e existem escolhas. Investigações sobre a construção social de futuros podem fazer a sociologia ser mais relevante. A pesquisa sobre futuros investiga tendências atuais para futuros possíveis e prováveis e, ao avaliar suas implicações sociais, contribuem para identificar aqueles que são desejáveis. Há muito ela abandonou suposições teleológicas ou deterministas, abraçando a ideia de contingência histórica, de um futuro aberto e da influência da agência humana. Ela é capaz de suprir os debates públicos com informações importantes acerca de tendências atuais, advertências sobre perigos iminentes e contribuir para a inclusão nas agendas de questões até então negligenciadas.

A pesquisa sobre futuros não existe em um vazio social. Interesses econômicos e políticos moldam-na por meio de dinheiro e poder, e através de financiamentos e decisões administrativas. Futuros são vendidos e revendidos várias vezes nos hipertrofiados mercados derivativos antes mesmo de o público ter a chance de, ao menos, refletir sobre suas implicações. A comoditização dos futuros produz recorrentes crises financeiras e econômicas que acarretam descontentamentos, mas uma sociologia que não trata do futuro é incapaz de fazer o público engajar-se em debates sobre outras alternativas. Como quaisquer pessoas, os pesquisadores de futuros têm responsabilidades para com os interesses daqueles que se utilizarão de seu trabalho, estejam suas questões enquadradas por interesses hegemônicos ou contribuam para revelar escolhas políticas valorativas que são apropriadas para a construção de um futuro mais inclusivo e democrático.

Markus S. Schulz é professor de Sociologia na Universidade de Illinois em Urbana-Champaign e presidente do International Sociological Association Research Committee on Futures Research (ISA-RCo7). É coautor da série de livros de seis volumes Internet und Politik in Lateinamerika (2004) e coeditor da Values and culture (20II). 


\section{NOTAS}

I Nos EUA, pesquisas sobre futuros são feitas em departamentos de pesquisa corporativa e por think-tanks políticos. Não há praticamente nenhuma área de concentração em pesquisas sobre futuros nos programas de sociologia do país. A Associação Americana de Sociologia (ASA) nem mesmo possui uma seção de futurologia como, por exemplo, a Associação Internacional de Sociologia (ISA), na qual é um de seus comitês mais antigos. No entanto, a escolha audaciosa da ASA em convocar seu Encontro Anual de 2012 sob o lema de "Utopias Reais" fornece uma nova abertura.

\section{REFERÊNCIAS BIBLIOGRÁFICAS}

Bachika, Reimon. (20 I I). Symbolism and values: Rationality and irrationality of culture. In: Values and culture: The social shaping of the future. Current Sociology, 59/2, p. 200-2 I 3 (número especial organizado por Reimon Bachika \& Markus S. Schulz). Bachika, Reimon \& Schulz, Markus S. (orgs.). (20I I). Values and culture: The social shaping of the future. Current Sociology, 59/2 (número especial).

Beck, Klaus; Glotz, Peter \& Vogelsang, Gregor. (2000). Die Zukunft des Internet: Internationale Delphi-Befragung zur Entwicklung der Online-Kommunikation. Konstanz: UVK Medien Beilharz, Peter. (2009). Socialism and modernity. Minneapolis: University of Minnesota Press.

Bell, Daniel. (I968). Toward the year 2000. Boston, MA: Houghton Mifflin Company.

Bell, Wendell. (I997a). Foundations of future studies: Human science for a new era. (Vol. I: History, purposes, and knowledge). New Brunswick, NJ: Transaction Publishers.

Bell, Wendell. (1997b). Foundations of future studies: Human science for a new era. (Vol. 2: Values, objectivity, and the good society). New Brunswick, NJ: Transaction Publishers.

Boudon, Raymond. (2002). Déclin de la morale? Déclin des valeurs? Paris: PUF.

Boulding, Elise \& Boulding, Kenneth E. (I995). The future: Images and processes. Thousand Oaks, CA: Sage.

Burawoy, Michael. (2005). For public sociology (2004 ASA Presidential Address). American Sociological Review, 70/ I, p. 4-28. 
Calhoun, Craig (org.). (I992). Habermas and the public sphere. Cambridge, MA: MIT Press.

Cardoso, Fernando Henrique \& Faletto, Enzo. (I979). Dependency and development in Latin America. Berkeley: University of California Press.

Casanova, José. (20I I). Cosmopolitanism, the Clash of Civilizations, and multiple modernities. In: Values and culture: The social shaping of the future. Current Sociology, 59/2, p. 252267 (número especial organizado por Reimon Bachika \& Markus S. Schulz).

Castoriadis, Cornelius. (I99I). Philosophy, power, autonomy: Essays in political philosophy. Oxford: Oxford University Press.

Cohen, Jean \& Arato, Andrew. (I992). Civil society and political theory. Cambridge, MA: MIT Press.

Comte, Auguste. (I968 [1852]). System of positive polity. Vol. 2. Nova York: Burt Franklin.

Comte, Auguste. (I968 [I853]). System of positive polity. Vol. 3. Nova York: Burt Franklin.

Comte, Auguste. (I957 [I848]). A general view of positivism. Nova York: Speller.

Comte, Auguste. (I855 [I830-I842]). The positive philosophy of Auguste Comte. Tradução de Harriet Martineau. Nova York: Blanchard.

Dewey, John. (1927). The public and its problems. Nova York: Holt.

Darwin, Charles. (1869). On the origin of species by means of natural selection, or the preservation of favoured races in the struggle for life. 5a ed. Londres: John Murray.

Darwin, Charles. (I859). On the origin of species by means of natural selection, or the preservation of favoured races in the struggle for life. Primeira edição. Londres: John Murray.

Durkheim, Émile. (I990). On morality and society: Selected writings. Edição e Introdução de Robert N. Bellah. Chicago: The University of Chicago Press.

Durkheim, Émile. (I984 [1893]). The division of labour in society. Nova York: The Free Press.

Durkheim, Émile. (I 982 [I895]). Rules for the sociological method. Nova York: The Free Press. 
Durkheim, Émile. (I966 [I897]). Suicide: A study in sociology. Nova York: The Free Press.

Durkheim, Émile. (I965 [I9I2]). The elementary forms of the religious life. Nova York: The Free Press.

Eisenstadt, Shmuel N. (org.). (2002). Multiple modernities. New Brunswick, NJ: Transaction Publishers.

Emirbayer, Mustafa \& Sheller, Mimi. (I999). Publics in history. Theory and Society, 28/I, p. I45-I97.

Emirbayer, Mustafa \& Mische, Ann. (I998). What is agency? American Journal of Sociology, I03, p. 962-1023.

Fals Borda, Orlando. (1987). The application of participatory action-research in Latin America. International Sociology, 2/4, p. 329-347.

Frank, Andre Gunder. (1967). Capitalism and Underdevelopment in Latin America. Nova York: Monthly Review Press.

Gordon, Theodore. J. \& Helmer, Olaf. (I964). Report on a long range forecasting study. Santa Monica, CA: Rand, Report $\mathrm{n}^{\circ}$ $\mathrm{R}-2982$.

Gore, Al. (2006). An inconvenient truth: The planetary emergency of global warming and what we can do about it. Emmaus, PA: Rodale Press.

Habermas, Jürgen. (I992 [1962]). The structural transformation of the public sphere: An inquiry into a category of bourgeois society. Cambridge, MA: MIT Press.

Habermas, Jürgen. (I985). Die Krise des Wohlfahrtsstaates und die Erschöpfung utopischer Energien. In: Die Neue Unübersichtlichkeit. Frankfurt am Main: Suhrkamp, p. I4I-I63. Huntington, Samuel P. (1996). The clash of civilizations and the remaking of world order. Nova York: Simon \& Schuster. Joas, Hans. (1992). Die Kreativität des Handelns. Frankfurt am Main: Suhrkamp.

Jungk, Robert \& Galtung, Johan (orgs.). (I969). Mankind 2000. Londres: Allen and Unwin.

Kahn, Hermann \& Wiener, Anthony. (1967). The year 2000: A framework for speculation on the next thirty-three years. Nova York: Macmillan.

Koselleck, Reinhart. (I989). Vergangene Zukunft: Zur Semantik geschichtlicher Zeiten. Frankfurt am Main: Suhrkamp. 
Küng, Hans. (I999). A global ethic in world politics: The middle way between "real politics" and "ideal politics". International Journal of Politics, Culture, and Society, I3/I, p. 30-37.

Latham, Robert \& Sassen, Saskia. (2005). Digital formations: Constructing an object of study. In: Digital formations: IT and new architectures in the global realm. Princeton: Princeton University Press, p. I-34.

Mannheim, Karl. (1936). Ideology and utopia: An introduction to the sociology of knowledge. Nova York: Harcourt, Brace.

Marx, Karl. (I978 [I87I]). Class struggles in France, I 848-1850. In: Tucker, Robert C. (org.). The Marx-Engels reader. $2 \mathrm{a}$ ed. Nova York: W. W. Norton.

Marx, Karl. (1978 [1867]). Capital. In: Tucker, Robert C. (org.). The Marx-Engels reader. $2 \mathrm{a}$ ed. Nova York: W. W. Norton.

Marx, Karl. (I978 [1859]). A contribution to the critique of political economy. In: Tucker, Robert C. (org.). The Marx-Engels reader. $2 \mathrm{a}$ ed. Nova York: W. W. Norton.

Marx, Karl. (I978 [1857-1858]). The Grundrisse. In: Tucker, Robert C. (org.). The Marx-Engels reader. 2a ed. Nova York: W. W. Norton.

Marx, Karl. (I978 [1852]). The Eighteenth Brumaire of Louis Bonaparte. In: Tucker, Robert C. (org.). The Marx-Engels reader. 2 a ed. Nova York: W. W. Norton.

Marx, Karl. (I978 [1845/I846]). The German ideology. In: Tucker Robert C. (org.). The Marx-Engels reader. $2 \mathrm{a}$ ed. Nova York: W. W. Norton.

Marx, Karl. (I978 [1845]). Theses on Feuerbach. In: Tucker, Robert C. (org.). The Marx-Engels reader. 2a ed. Nova York: W. W. Norton.

Marx, Karl. (I978 [1844]). Economical and philosophical manuscripts of I 844. In: Tucker, Robert C. (org.). The Marx-Engels reader. $2 \mathrm{a}$ ed. Nova York: W. W. Norton.

Marx, Karl. (I 978 [ I 844]). The holy family. In: Tucker, Robert C. (org.). The Marx-Engels reader. $2 \mathrm{a}$ ed. Nova York: W. W. Norton.

Marx, Karl. (I978 [I843]). Contribution to the Critique of Hegel's philosophy of right. In: Tucker, Robert C. (org.). The Marx-Engels reader. 2 a ed. Nova York: W. W. Norton. 
Marx, Karl. (I978 [1843]). On the Jewish question. In: Tucker, Robert C. (org.). The Marx-Engels reader. $2 \mathrm{a}$ ed. Nova York: W. W. Norton.

Marx, Karl \& Engels, Friedrich. (I978 [1848]). Manifesto of the Communist Party. In: Tucker, Robert C. (org.). The Marx-Engels reader. 2 a ed. Nova York: W. W. Norton.

Masini, Eleonora (org.). (1983). Visions of desirable societies. Oxford: Pergamon.

McLuhan, Marshall. (I964). Understanding media: The extensions of man. Nova York: Signet.

Meadows, Donella H.; Meadows, Dennis L.; Randers, Jørgen \& Behrens III, William W. (I972). The limits to growth: A report for the Club of Rome's Project on the predicament of mankind. Nova York: Universe Books.

Melucci, Alberto. (1996). Challenging codes: Collective action in the information age. Cambridge: Cambridge University Press.

Mommsen, Wolfgang J. (I963). Zum Begriff der "plebiszitären Führerdemokratie" bei Max Weber. Kölner Zeitschrift für Soziologie und Sozialpsychologie, I5, p. 295-323.

Nederveen Pieterse, Jan (org.). (2000). Global futures: Shaping globalization. Londres: Zed Books.

Offe, Claus. (1987). The utopia of the zero-option: Modernity and modernization as normative political criteria. Praxis International, 7/I, p. I-24.

Revkin, Andrew C. (2004). Bush vs. the Laureates: How science became a partisan issue. New York Times, I4 de outubro. Schuchardt, Bastian \& Schirmer, Michael (orgs.). (2005). Klimawandel und Küste: Die Zukunft der Unterweserregion. Berlim: Springer.

Schulz, Markus S. (20I I). The values of global futures. Current Sociology, 59/2, p. 268-273.

Schulz, Markus S. (2009). Structured modes of interplay and the modeling of digital futures. In: Denis, Ann \& Kalekin-Fishman, Devorah (orgs.). The ISA handbook of contemporary sociology. Londres: Sage/ISA, p. 29I-304.

Schulz, Markus S. (2007a). The role of the internet in transnational mobilization: A case study of the Zapatista movement, I994-2005. World Society Studies, 2007/I, p. I 29-I56. 
Schulz, Markus S. (2007b). Novas mídias, mobilização transnacional e as reestruturações das esferas públicas. Civitas Revista de Ciências Sociais, 7/2, p. I08-I 28.

Schulz, Markus S. (2002). Mexiko zwischen Demokratisierung und Liberalisierung: Internet und Politik in Lateinamerika, Vol. 4. Frankfurt am Main: Vervuert.

Schulz, Markus S. (200 Ia). Democracia y cambio de los medios en América Latina. Perfiles Latinoamericanos, Io/ı 8, p. 9-28. Schulz, Markus S. (200Ib). Der langfristige soziale Wandel und seine Interpretation in ökonometrische Langfristprognosen. Bremer Diskussionspapiere zur ökonomischen Klimafolgenforschung, 8, p. I-55.

Schulz, Markus S. (I999). Internationale Zukunftsstudien zur langfristigen sozialen Entwicklung. Bremer Diskussionspapiere zur ökonomischen Klimafolgenforschung, 6, p. I-35.

Schulz, Markus S. (I998). Collective action across borders: Opportunity structures, network capacities, and communicative praxis in the age of advanced globalization. Sociological Perspectives, 4I/3, p. 587-6I6.

Schumpeter, Joseph A. (I975 [I950]). Capitalism, socialism, and democracy. Nova York: Harper.

Shulman, Seth. (2006). Undermining science: Suppression and distortion in the Bush administration. Berkeley: University of California Press.

Slaughter, Richard A. (2002). Where now for futures studies? Futures, 34/3-4, p. 229-234.

Smith, Adam. (2003 [1776]). The wealth of nations. Nova York: Bantam.

Spencer, Herbert. (I874). The study of sociology. Londres: H.S. King.

Spencer, Herbert. (I 864). Principles of biology. Londres: Williams and Norgate.

Spencer, Herbert. (I85I). Social statics, or, the conditions essential to human happiness specified, and the first of them developed. Londres: John Chapman.

Tocqueville, Alexis de. (I990 [I835-I840]). Democracy in America. Nova York: Vintage.

Touraine, Alain. (198I). The voice and the eye: An analysis of social movements. Cambridge: Cambridge University Press. 
Touraine, Alain; Dubet, François; Wieviorka, Michel \& Strzelecki, Jan. (1983). Solidarity: The analysis of a social movement: Poland, I980-I98I. Cambridge, UK: Cambridge University Press.

Weber, Max. (I99I [I9I7]). Der Sinn der "Wertfreiheit" der soziologischen und ökonomischen Wissenschaften. In: Schriften zur Wissenschaftslehre. Stuttgart: Reclam, p. I76236.

Weber, Max. (I99I [1905]). The Protestant Ethic and the Spirit of Capitalism. Tradução de Talcott Parsons, Introdução de Anthony Giddens. Londres: HarperCollins.

Weber, Max. (I99I [I 904]). Die "Objektivität" sozialwissenschaftlicher und sozialpolitischer Erkenntnis. In: Schriften zur Wissenschaftslehre. Stuttgart: Reclam, p. 2 I-IOI.

Weber, Max. (1978). Economy and society. An outline of interpretative sociology. Editado por Guenther Roth e Claus Wittich. Berkeley: University of California Press.

Weber, Max. (1958). From Max Weber. Essays in sociology. Tradução, edição e introdução de H. H. Gerth e C. Wright Mills. Nova York: Oxford University Press.

Weber, Max. (1923). Wirtschaftsgeschichte: Abriss der universalen Sozial - und Wirtschaftsgeschichte. Berlim: Duncker \& Humblot.

Welsch, Wolfgang. (1996). Vernunft: Die zeitgenössische Vernunftkritik und das Konzept der transversalen Vernunft. Frankfurt am Main: Suhrkamp.

Wright, Erik Olin. (20I0). Envisioning real utopias. Nova York: Verso. 
Palavras-chave

Futuro;

História da sociologia; Imaginação; Público;

Teoria sociológica.

Keywords

Future;

History of sociology; Imagination; Public; Sociological theory.

\section{DEBATENDO FUTUROS: TENDÊNCIAS GLOBAIS, VISÕES ALTERNATIVAS E DISCURSO PÚBLICO} Resumo

Este artigo explora a difícil relação entre uma sociologia voltada para o futuro e o debate público no momento em que suposições implícitas e operacionalizações explícitas sobre o futuro mudam da noção de determinismo para a de contingência e conflito. Os problemas não são apenas teóricos, mas também práticos, visto que as escolhas metodológicas prévias moldam a relação da sociologia com o debate público e sua capacidade de enfrentar os desafios que surgem nos dias de hoje. Desde seu surgimento, a sociologia esteve voltada para reflexões coletivas acerca não apenas das condições sociais passadas ou presentes, mas também das possibilidades de mudança. Transformações nas constelações epistemológicas, institucionais e sociais moldaram a expansão, o desaparecimento e o ressurgimento de orientações para o futuro. Distanciando-se da prática da previsão, a pesquisa sociológica sobre futuros concentra-se na dinâmica da imaginação e criação de futuros, tendências atuais, cenários prováveis e possíveis e suas implicações sociais.

\section{DEBATING FUTURES: GLOBAL TRENDS, ALTERNATIVE VISIONS, AND PUBLIC DISCOURSE}

\section{Abstract}

This paper explores the uneasy relationship between forward-oriented sociology and public debate as implicit assumptions and explicit operationalizations of the future shift from determinism to contingency and contention. The stakes are not merely theoretical but also practical because methodological pre-decisions shape sociology's relation to public debate and its abilities to tackling the emergent challenges of our time. Sociology was geared since its inception toward collective reflection of not only present or past conditions of social existence but also of potentials for change. Shifting epistemological, institutional, and social constellations shaped the expansion, evasion, and re-emergence of future orientations. Distancing itself from the business of prediction, sociological futures research is focused on the dynamics of imagining and making futures, current trends, likely and possible scenarios, and their social implications. 